\title{
Glycine Receptors in CNS Neurons as a Target for Nonretrograde Action of Cannabinoids
}

\author{
Natalia Lozovaya, ${ }^{1 *}$ Natalia Yatsenko, ${ }^{1 \star}$ Andrey Beketov, ${ }^{1}$ Timur Tsintsadze, ${ }^{1}$ and Nail Burnashev ${ }^{2}$ \\ ${ }^{1}$ Department of Cellular Membranology, Bogomoletz Institute of Physiology, 01204 Kiev, Ukraine, and ${ }^{2}$ Departments of Experimental Neurophysiology and \\ Medical Pharmacology, Center for Neurogenomics and Cognitive Research, and Vrije Universiteit Medical Center, Vrije Universiteit Amsterdam, 1081 HV \\ Amsterdam, The Netherlands
}

\begin{abstract}
At many central synapses, endocannabinoids released by postsynaptic cells act retrogradely on presynaptic G-protein-coupled cannabinoid receptors to inhibit neurotransmitter release. Here, we demonstrate that cannabinoids may directly affect the functioning of inhibitory glycine receptor (GlyR) channels. In isolated hippocampal pyramidal and Purkinje cerebellar neurons, endogenous cannabinoids anandamide and 2-arachidonylglycerol, applied at physiological concentrations, inhibited the amplitude and altered the kinetics of rise time, desensitization, and deactivation of the glycine-activated current $\left(I_{G l y}\right)$ in a concentration-dependent manner. These effects of cannabinoids were observed in the presence of cannabinoid CB1/CB3, vanilloid receptor 1 antagonists, and the G-protein inhibitor GDP $\beta S$, suggesting a direct action of cannabinoids on GlyRs. The effect of cannabinoids on $I_{\text {Gly }}$ desensitization was strongly voltage dependent. We also demonstrate that, in the presence of a $\mathrm{GABA}_{\mathrm{A}}$ receptor antagonist, GlyRs may contribute to the generation of seizure-like activity induced by short bursts (seven stimuli) of high-frequency stimulation of inputs to hippocampal CA1 region, because this activity was diminished by selective GlyR antagonists (strychnine and ginkgolides B and J). The GlyR-mediated rhythmic activity was also reduced by cannabinoids (anandamide) in the presence of a $\mathrm{CB} 1$ receptor antagonist. These results suggest that the direct inhibition of GlyRs by endocannabinoids can modulate the hippocampal network activity.
\end{abstract}

Key words: glycine receptor; cannabinoids; hippocampus; cerebellum; seizure-like activity; desensitization

\section{Introduction}

Cannabinoids influence brain function primarily by activating the G-protein-coupled cannabinoid CB1 receptors (CB1Rs), which are expressed throughout the brain at high levels. Several endogenous lipids, including anandamide (AEA) and 2-arachidonylglycerol (2-AG), have been identified as CB1R ligands (Devane et al., 1992; Di Marzo et al., 1994; Stella et al., 1997). The synthesis of endocannabinoids is triggered by cytoplasmic $\mathrm{Ca}^{2+}$. Endocannabinoids rapidly released from neurons after depolarization mediate some forms of activity-dependent short- and long-term presynaptic modulation of synaptic transmission. These include depolarization-induced suppression of inhibition, depolarization-induced suppression of excitation (Kreitzer and Regehr, 2001; Ohno-Shosaku et al., 2001; Wilson and Nicoll, 2001, 2002; Diana et al., 2002) as well as long-term depression of inhibitory synapses, which selectively "prime" nearby excitatory synapses, facilitating subsequent induction of

\footnotetext{
Received March 12, 2005; revised June 8, 2005; accepted June 12, 2005.

This work was supported by United States Civilian Research and Development Foundation Grant UKB1-2615-KV04. We thank E. Kondratskaya, A. Fisunov, V. Tsintsadze, C. Holmgren, and A. Brussaard for the helpful comments on this manuscript and 0. Krishtal, A. N. M. Schoffelmeer, and T. J. de Vries for general support.

*N.L. and N.Y. contributed equally to this work.

Correspondence should be addressed to Dr. Nail Burnashev, Department of Experimental Neurophysiology, Faculty of Earth and Life Sciences, Vrije Universiteit Amsterdam, DE Boelelaan 1087, 1081 HV Amsterdam, The Netherlands. E-mail: nail@bio.vu.nl.

DOI:10.1523/JNEUROSCI.0977-05.2005

Copyright $\odot 2005$ Society for Neuroscience $\quad$ 0270-6474/05/257499-08\$15.00/0
}

long-term potentiation (Chevaleyre and Castillo, 2004). In particular, in the hippocampus, cannabinoids acting presynaptically modulate both glutamatergic and GABAergic neurotransmission (Misner and Sullivan, 1999; Hajos et al., 2000; Hoffman and Lupica, 2000).

CB1R activation accounts for most of the central effects of cannabimimetic drugs. Nevertheless, although most of the behavioral effects of cannabinoids are absent in CB1R-deficient mice, cannabinoids (in particular, AEA) still induce catalepsy and analgesia and decrease spontaneous activity in these mice (Di Marzo et al., 1994; Baskfield et al., 2004). Furthermore, in mice, the typical cannabimimetic effects of AEA on spontaneous activity, body temperature, and pain perception are not reversed by treatment with the selective $C B 1$ receptor antagonist $N$-piperidino-5-(4-chlorophenyl)-1-(2,4dichlorophenyl)-4-methylpyrazole-3-carboxamide (SR141716A) (Adams et al., 1998). These data indicate the existence of functionally important targets for brain cannabinoid signaling in addition to CB1Rs.

Local alignment of amino acid sequences of cannabinoid receptors and glycine receptor (GlyR) subunits revealed that GlyRs contain few fragments that display a high level of homology with the regions within $\mathrm{CB} 1 \mathrm{R}$ and $\mathrm{CB} 2 \mathrm{R}$, which are suggested to be responsible for agonist binding (Mahmoudian, 1997; Tao et al., 1999; Shim et al., 2003) (supplemental Figs. S1-S4, available at www.jneurosci.org as supplemental material). This prompted us to study possible functional interaction between cannabinoid agonists and GlyR. 


\section{Materials and Methods}

Materials. All of the chemicals for intracellular and extracellular solutions were purchased from Sigma (St. Louis, MO). ( $R)-(+)-(2,3$-dihydro-5methyl-3-(4-morpholinylmethyl)pyrrolo(1,2,3-de)-1,4-benzoxazin-6yl)-1-naphthalenylmethanone (WIN 55,212-2), AEA, and 2-AG were obtained from Tocris Cookson (Bristol, UK). Ginkgolides B and J were kindly provided by Dr. S. Chatterjee (Dr. Willmar Schwabe Group, Karlsruhe, Germany).

Cell preparation. Wistar rats (12-17 d of age) were decapitated under ether anesthesia, and the hippocampus (or cerebellum) was removed and cut into slices $(300-500 \mu \mathrm{m})$ in a solution containing the following (in mM): $150 \mathrm{NaCl}, 5 \mathrm{KCl}, 1.25 \mathrm{NaH}_{2} \mathrm{PO}_{4}, 26 \mathrm{NaHCO}_{3}, 1.1 \mathrm{MgCl}_{2}$, and 10 glucose, $\mathrm{pH}$ 7.4. Then, the slices were incubated for $10 \mathrm{~min}$ (hippocampal) and for $30 \mathrm{~min}$ (cerebellar) at $32^{\circ} \mathrm{C}$ with $0.5 \mathrm{mg} / \mathrm{ml}$ of protease (type XXIII) from Aspergillus oryzae. Single pyramidal cells from CA1 and CA3 stratum pyramidale layers were isolated by vibrodissociation locally in the stratum pyramidale, and Purkinje cells were isolated by successive trituration of the small pieces of the Purkinje cell layer of the cerebellum through several fire-polished pipettes with opening diameters from 0.5 to $0.1 \mathrm{~mm}$. CA3 and CA1 hippocampal pyramidal and cerebellar Purkinje neurons were identified by their characteristic form and partially preserved dendritic arborization.

After isolation, the cells were usually suitable for recordings for 2-4 h. Throughout the entire procedure, the solutions with the slices were continuously saturated with $95 \% \mathrm{O}_{2}$ and $5 \% \mathrm{CO}_{2}$ gas mixture to maintain $\mathrm{pH}$ 7.4. The tested substances were dissolved in DMSO to a stock concentration of $10 \mathrm{~mm}$ and kept frozen at $-40^{\circ} \mathrm{C}$ in daily aliquots. The substances were dissolved in external saline to their final concentration immediately before the experiments.

Current recordings. Glycine-activated currents in isolated neurons were induced by the step application of agonists in the "concentrationclamp" mode (Krishtal et al., 1983), using the computerized PharmaRobot set-up (Pharma-Robot, Kiev, Ukraine). This equipment allows a complete change of saline within $15 \mathrm{~ms}$. Transmembrane currents were recorded using a conventional patch-clamp technique in the whole-cell configuration. Patch-clamp electrodes were pulled with a horizontal puller (Sutter Instruments, Novato, CA) and had an internal tip diameter between 1.4 and $1.8 \mu \mathrm{m}$ and a tip resistance between 2.5 and $5 \mathrm{M} \Omega$. The intracellular solution contained the following (in mM): 70 Tris- $\mathrm{PO}_{4}, 5$ EGTA, 40 TEA-Cl (tetraethylammonium chloride), 30 Tris-Cl, $5 \mathrm{Mg}$ ATP, and 0.5 GTP, pH 7.2. The composition of extracellular solution was as follows (in mM): $130 \mathrm{NaCl}, 3 \mathrm{CaCl}_{2}, 5 \mathrm{KCl}, 2 \mathrm{MgCl}_{2}, 10$ HEPES$\mathrm{NaOH}$, and $0.1 \mu \mathrm{M}$ TTX, pH 7.4. Recording of the currents was performed using patch-clamp amplifiers (Dagan, Minneapolis, MN). To avoid activation of the $\mathrm{GABA}_{\mathrm{A}}$ receptor $\left(\mathrm{GABA}_{\mathrm{A}} \mathrm{R}\right)$ by glycine, the $\mathrm{GABA}_{\mathrm{A}} \mathrm{R}$ antagonist bicuculline $(10 \mu \mathrm{M})$ was routinely added to all extracellular solutions. Transmembrane currents were filtered at $3 \mathrm{kHz}$, stored, and analyzed with an IBM-PC computer (IBM Corporation, White Plains, NY) using homemade software. Glycine responses were recorded with a $3 \mathrm{~min}$ interval. All experiments were performed at room temperature $\left(19-24^{\circ} \mathrm{C}\right)$.

Hippocampal slice experiments. During preincubation, the slices (300$400 \mu \mathrm{m}$ thick) obtained from 17 - to 19 -d-old rats were kept fully submerged in $\mathrm{HCO}_{3}$-buffered artificial CSF (ACSF) as follows (in mM): 135 $\mathrm{NaCl}, 5 \mathrm{KCl}, 26 \mathrm{NaHCO}_{3}, 1.5 \mathrm{CaCl}_{2}, 1.5 \mathrm{MgCl}_{2}$, and 20 glucose, $\mathrm{pH} 7.4$, equilibrated with $95 \% \mathrm{O}_{2} / 5 \% \mathrm{CO}_{2}$. The experiments were conducted in the same solution, containing $2 \mathrm{mM} \mathrm{CaCl}_{2}$ and $1 \mathrm{mM} \mathrm{MgCl}_{2}$ at $32-34^{\circ} \mathrm{C}$. The nominally $\mathrm{HCO}_{3}$-free ACSF was saturated with $100 \% \mathrm{O}_{2}$, and $26 \mathrm{~mm}$ $\mathrm{NaHCO}_{3}$ was replaced with HEPES acid, and $\mathrm{pH}$ was titrated to 7.4 with $\mathrm{NaOH}$.

Field potentials were recorded in the stratum radiatum using a tungsten electrode. To stimulate the Schaffer collateral-commissural pathway, a bipolar $\mathrm{Ni} / \mathrm{Cr}$ electrode was positioned on the surface of the slice. The current intensity of test stimuli $(25-50 \mu \mathrm{A})$ was set to produce field potentials of half-maximal amplitude. Current pulses were delivered through the isolated stimulator HG 203 (Hi-Med, London, UK) at $0.066-0.2 \mathrm{~Hz}$.

The care and use of animals for all experiments followed the guidelines
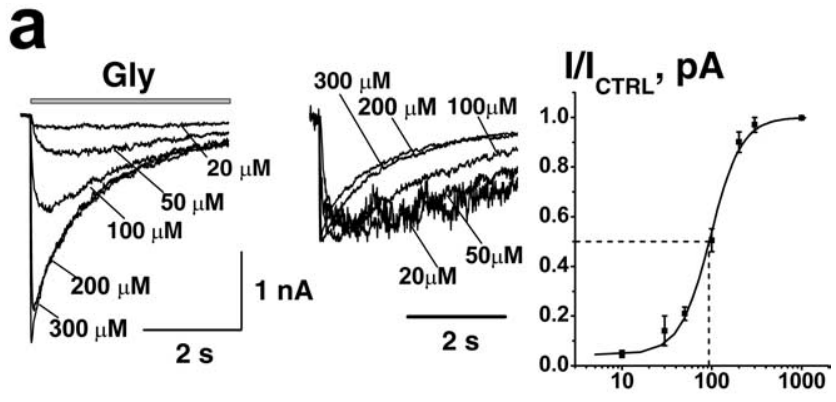

b
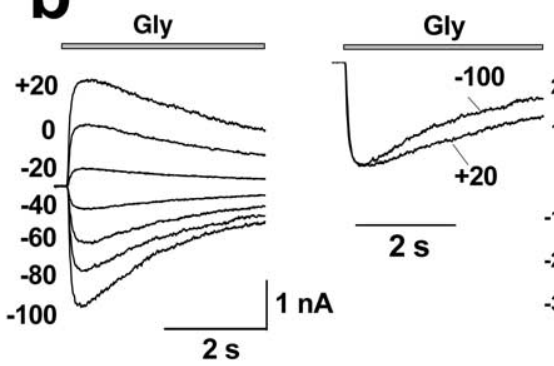

[Gly], $\mu \mathrm{M}$

Figure 1. a, Agonist concentration dependence of glycine-induced current $\left(I_{G l y}\right)$. Left, Family of $I_{\text {Gly }}$ representative traces at increasing Gly concentration ranging from 20 to $300 \mu \mathrm{M}$. $I_{\text {Gly }}$ was recorded in a CA3 hippocampal neuron by conventional whole-cell techniques. Responses were evoked by $4 \mathrm{~s}$ application of Gly (indicated here and in subsequent figures by gray bars above traces) at a holding potential of $-100 \mathrm{mV}$ in the presence of $10 \mu \mathrm{m}$ bicuculline. Middle, The same traces normalized to the peak amplitude. Right, Normalized averaged concentrationresponse curve of $I_{G l y}(n=4) \cdot \boldsymbol{b}$, Current-voltage relationship of $I_{G l y}$. Left, The family of representative traces of current induced by $100 \mu \mathrm{m}$ Gly at various holding potentials from -100 to $+20 \mathrm{mV}$ with a $20 \mathrm{mV}$ step. Middle, Traces obtained at -100 and $+20 \mathrm{mV}$ are superimposed and normalized. Right, $I-V$ of peak $I_{\text {Gly' }}$ measured with $100 \mu \mathrm{m} \mathrm{Gly.}$

and protocols approved by our institutional Animal Care and Use Committee (protocol number no2/0204).

Data analysis. The effect of the substance was measured as the mean ratio $I / I_{\text {CTRL }}$, where $I$ is the amplitude of the current under the action of the substance, and $I_{\mathrm{CTRL}}$ is the amplitude of the current in control saline. The data were fitted using the Hill equation $I / I_{\mathrm{CTRL}}=1-1 /\left[1+\left(\mathrm{IC}_{50} /\right.\right.$ $\left.[S])^{n_{\mathrm{H}}}\right]$, where $[S]$ is the concentration of the substance, $\mathrm{IC}_{50}$ is the halfinhibition concentration of the substance, and $n_{\mathrm{H}}$ is the Hill coefficient.

The $I_{\text {Gly }}$ desensitization and deactivation kinetics (after 4-s-long pulses) were fitted with monoexponential function. Exponential curve fitting was performed using the simplest algorithm least-squares routines, with single exponential equations of the form $y=y_{\mathrm{o}}+A_{1} e^{-(x-x \mathrm{o}) / \tau}$, where $\tau_{\mathrm{des}}$ is the time constant of $I_{\mathrm{Gly}}$ desensitization, and $\tau_{\text {deac }}$ is the time constant of $I_{\mathrm{Gly}}$ deactivation. The onset kinetics of $I_{\text {Gly }}$ was estimated as the $20-80 \%$ rise time $\left(t_{\mathrm{on}}\right)$.

Fourier transformations of 2-s-long epochs of epileptiform discharges were performed using Origin v7.0 software (OriginLab, Northampton, MA).

Data were statistically compared using Student's $t$ test at a significance level of $p=0.05$. Data are expressed as mean \pm SEM.

\section{Results}

Glycine-activated currents in isolated hippocampal neurons Application of glycine to CA1 and CA3 pyramidal neurons isolated from the hippocampus of neonatal rats (12-17 $d$ of age) in the presence of the $\mathrm{GABA}_{\mathrm{A}} \mathrm{R}$ antagonist bicuculline elicited wholecell chloride currents in line with previous studies (Krishtal et al., 1988; Shirasaki et al., 1991; Chattipakorn and McMahon, 2002). The amplitude, onset, and desensitization kinetics of glycine-activated currents $\left(I_{\mathrm{Gly}}\right)$ were dependent on glycine concentration (Fig. 1a). The $\mathrm{EC}_{50}$ value of glycine was $91 \pm 5 \mu \mathrm{M}, n=4$, with a Hill coefficient of $2.2 \pm 0.2$, which corresponds well with the values reported 
for acutely isolated cells from the hypothalamus $(90 \mu \mathrm{M})$ (Akaike and Kaneda, 1989) or acutely isolated hippocampal neurons (69 $\mu \mathrm{M})$ (Kondratskaya et al., 2002). The reversal potential of $I_{\mathrm{Gly}}$ in our experimental conditions was between -35 and $-25 \mathrm{mV}$, with an average value of $-28.15 \pm 2.2 \mathrm{mV}$ (Fig. $1 b)(n=4)$. $I_{\text {Gly }}$ was completely and reversibly blocked by specific GlyR blockers strychnine (1 $\mu \mathrm{M})$ and gingkolide $\mathrm{B}(10 \mu \mathrm{M})$ (data not shown). These results and the following data were obtained from CA3 pyramidal neurons; however, qualitatively similar results were obtained in CA1 neurons.

\section{Modulation of glycine-activated currents by endogenous cannabinoids in isolated hippocampal neurons}

Both endogenous cannabinoids, 2-AG and AEA, at physiological concentrations $(0.2-2 \mu \mathrm{M})$ strongly inhibited the peak $I_{\mathrm{Gly}}$ (Fig. $2 a, b) . I / I_{\text {CTRL }}\left({ }^{*} 100 \%\right)$ values were $40 \pm 7 \%(p<0.02 ; n=4)$ with $1 \mu \mathrm{M} 2-\mathrm{AG}$ and $20 \pm 7 \%(p<0.02 ; n=4)$ with $1 \mu \mathrm{M}$ AEA. Meanwhile, the $I_{\text {Gly }}$ onset and desensitization were accelerated in the presence of both endocannabinoids (Fig. 2). For example, the time constant of $I_{\mathrm{Gly}}$ desensitization $\left(\tau_{\text {des }}\right)$ decreased to $55 \pm 6 \%$ $(p<0.001 ; n=4)$ of control in the presence of $2-\mathrm{AG}$ and to $40 \pm$ $15 \%(p<0.02 ; n=4)$ in the presence of AEA. Figure 2 illustrates the averaged ratios of $I_{\mathrm{Gly}}$ peak, $\tau_{\mathrm{des}}$, and $t_{\mathrm{on}}$ values in the presence of 2-AG (Fig. 2c) and AEA (Fig. 2d) to control. The effects of cannabinoids were concentration dependent (Fig. 2). The peak amplitude, rise time, and $\tau_{\mathrm{des}}$ of $I_{\mathrm{Gly}}$ slowly and partially recovered after washout of both drugs. No changes of the holding current were observed in the presence of cannabinoids.

Endogenous cannabinoids significantly reduced peak and $\tau_{\text {des }}$ of $I_{\mathrm{Gly}}$ at all tested holding potentials. However, the changes in the decay kinetics, induced by 2 -AG, were more pronounced at positive membrane potentials (Fig. $3 b$, f). At $+20 \mathrm{mV}$, $\tau_{\text {des }}$ decreased to $31 \pm 9 \%$ in the presence of $2-\mathrm{AG}$ compared with $55 \pm 6 \%$ at $-100 \mathrm{mV}(p<0.02 ; n=4)$. In contrast, the effects of endocannabinoids on the $I_{\mathrm{Gly}}$ onset did not display voltage dependence (Fig. 3c,g).

The current decay after removal of Gly represents transitions from active ligand-bound receptor states to inactive unbound states, including channel closure and glycine dissociation. In addition, desensitized receptors may reopen before agonist dissociation, prolonging deactivation (Jones and Westbrook, 1995). The fact that endocannabinoids accelerated the $I_{\mathrm{Gly}}$ desensitization suggested the possibility that $I_{\mathrm{Gly}}$ desensitization and deactivation are coupled. Indeed, acceleration of $I_{\mathrm{Gly}}$ desensitization by 2 -AG was accompanied by a significant slowdown of $I_{\mathrm{Gly}}$ deactivation (Fig. $3 d, h)$. At $-100 \mathrm{mV}$, the deactivation time constant $\left(\tau_{\text {deac }}\right)$ increased to $300 \pm 65 \%(p<0.01 ; n=3)$.

\section{Effects of WIN 55,212-2 on glycine-activated currents}

In contrast to endocannabinoids, the synthetic cannabinoid agonist WIN 55,212-2 $(1 \mu \mathrm{M})$ barely affected the $I_{\text {Gly }}$ peak amplitude $\left(I_{\text {WIN }} / I_{\text {CTRL }}\right.$ was $\left.107 \pm 2 \% ; n=8\right)$. However, it significantly and reversibly accelerated the desensitization as well as onset of $I_{\mathrm{Gly}}$, in a manner similar to 2-AG and AEA. The desensitization time constant, $\tau_{\text {des }}$, decreased to $59 \pm 4 \%(p<0.0001 ; n=11)$ of control in the presence of WIN 55,212-2, and $t_{\text {on }}$ decreased to $58 \pm 5 \%$ of control $(p<0.02 ; n=11)$.

The WIN 55,212-2-induced acceleration of desensitization and rise time of $I_{\mathrm{Gly}}$ exhibited clear concentration dependence (Fig. 4). It is noteworthy that WIN 55,212-2 at higher concentration induced weak inhibition of the peak currents (at $5 \mu \mathrm{M}, I_{\mathrm{WIN}} /$ $I_{\text {CTRL }}$ was $\left.65 \pm 5 \% ; p<0.02 ; n=5\right)$.

As in the case of endocannabinoids, prominent voltage dependence of the $I_{\mathrm{Gly}}$ desensitization observed in control condi- a
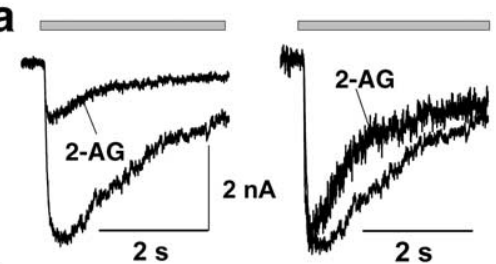

b
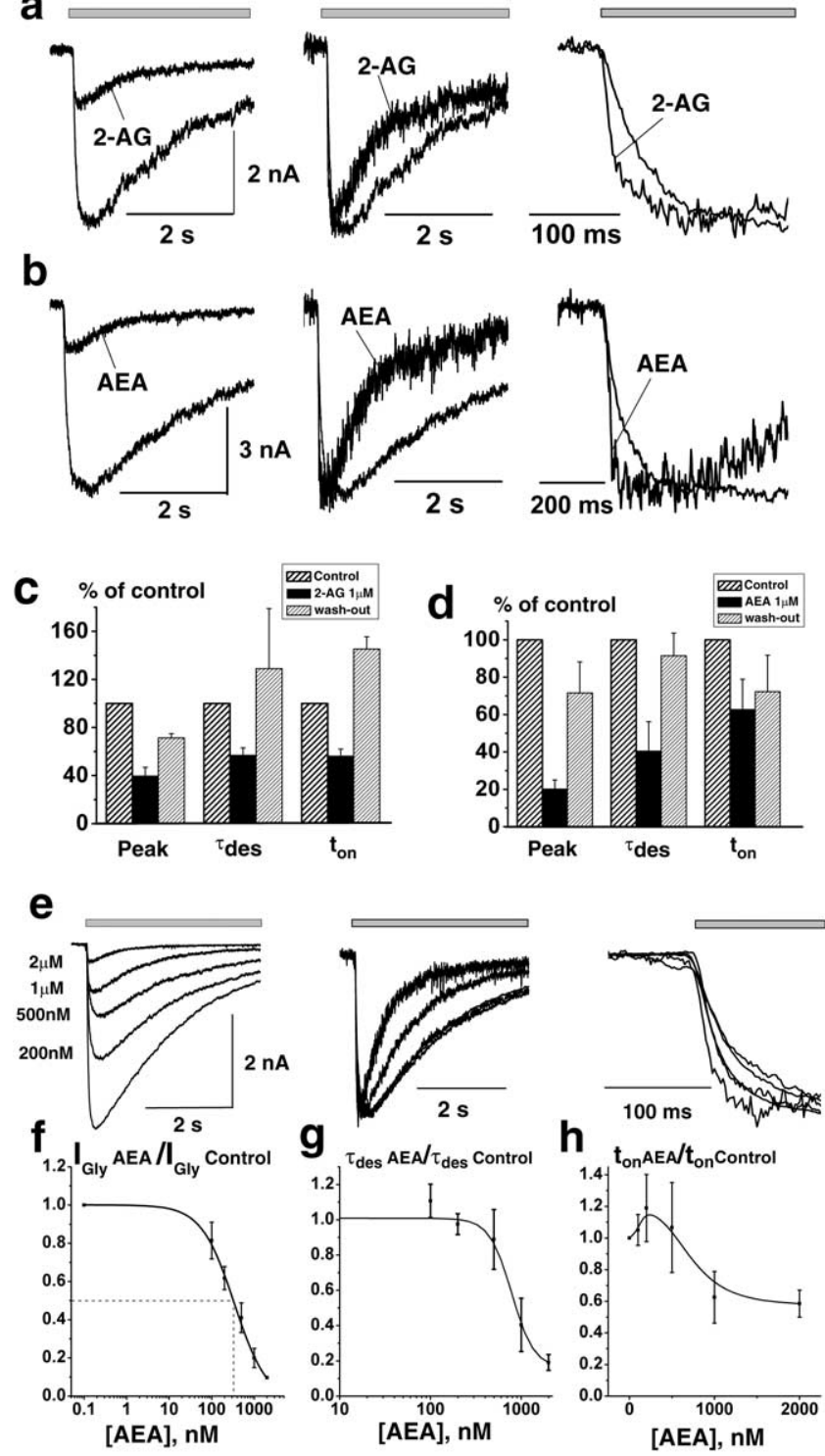

Figure 2. Modulation of $I_{G l y}$ by endogenous cannabinoids. $\boldsymbol{a}, \boldsymbol{b}$, Left, Representative traces of $I_{G l y}$ induced by $100 \mu \mathrm{m} \mathrm{Gly,} \mathrm{obtained} \mathrm{in} \mathrm{control} \mathrm{and} \mathrm{in} \mathrm{the} \mathrm{presence} \mathrm{of} 1 \mu \mathrm{M} 2-\mathrm{AG}(\boldsymbol{a})$ or $1 \mu \mathrm{M}$ AEA $(\boldsymbol{b})$. Middle and right, Corresponding traces are superimposed and normalized. The averaged numbers for changes of $I_{\text {Gly }}$ peak, $\tau_{\text {des }}$ and $20-80 \%$ rise time $\left(t_{\text {on }}\right)$ induced by 2-AG (c) and AEA (d). $\boldsymbol{e}-\boldsymbol{h}$, Concentration dependence of AEA effects on $I_{\text {Gly }} \cdot \boldsymbol{e}$, Left, Representative traces obtained at various concentrations of AEA ranged from $200 \mathrm{~nm}$ to $2 \mu \mathrm{m}$. Middle and right, Corresponding traces are normalized and superimposed. Summary plots showing the effect of increasing AEA concentrations on the amplitude $(\boldsymbol{f}), \tau_{\text {des }}(\boldsymbol{g})$, and $t_{\text {on }}(\boldsymbol{h})$ of $\left.\right|_{\text {Gly }}$ are shown $\left(V_{\mathrm{h}}=\right.$ $-100 \mathrm{mV} ; n=4)$. Data are plotted as a fraction of the maximal glycine current in control.

tions was practically eliminated in the presence of WIN 55,212-2. This corresponds to a much more pronounced effect of WIN 55,212-2 on the desensitization kinetics at depolarized potentials (Fig. 4). Indeed, the decrease of $\tau_{\text {des }}$ induced by application of WIN $55,212-2$ was $35 \pm 5 \%$ at $+20 \mathrm{mV}$ compared with $59 \pm 4 \%$ at $-100 \mathrm{mV}(p<0.02 ; n=4)$. However, in contrast to endocannabinoids and despite the pronounced changes in the $I_{\mathrm{Gly}}$ desensitization, no significant change of deactivation was observed even with high concentrations of WIN 55,212-2 (data not shown). Qualitatively similar effects of both endogenous and synthetic cannabinoids on GlyRs were observed in isolated Purkinje neurons (supplemental Fig. S5, available at www.jneurosci. org as supplemental material). 
The action of cannabinoids on GlyRs is not mediated by activation of $\mathrm{CB} 1 / \mathrm{CB} 3$, vanilloid receptors, or

G-protein activation

An important question is whether cannabinoid receptors are involved in the modulation of GlyRs. Although CB2Rs are not expressed in the brain (Munro et al., 1993), CB1Rs are abundantly expressed in the CA1 pyramidal layer of the hippocampus (Tsou et al., 1998). In addition to CB1R, a novel "vanilloid-like" CB3 receptor, which shares sensitivity to both cannabinoid and capsaicin receptor agonists, has been demonstrated recently in the hippocampus (Hajos et al., 2001). Furthermore, AEA is known as an agonist of vanilloid receptors, VR1 (Zygmunt et al., 1999, 2000). To test whether cannabinoid and/or vanilloid receptors are involved in modulation of GlyRs, the effects of cannabinoids were tested in the presence of the CB1R antagonist SR141716A or the CB3R antagonist capsazepine. Figure 5 shows that the effects of $1 \mu \mathrm{M} 2$-AG on $I_{\mathrm{Gly}}$ peak amplitude, decay, and onset kinetics were preserved in the presence of $\mathrm{CB} 1$ receptor antagonist SR141716A (Fig. 5a,e). No significant differences in 2-AG or AEAinduced effects on $I_{\mathrm{Gly}}$ desensitization and onset were observed in the presence of capsazepine (Fig. $5 c-f$ ).

To determine whether G-proteins mediate the actions of cannabinoids on GlyRs, the G-protein inhibitor GDP $\beta$ S was applied to the cells via the pipette solution. After $30 \mathrm{~min}$ of GDP $\beta$ S pretreatment, decay kinetics and rise time were accelerated by $2-\mathrm{AG}(1 \mu \mathrm{M})$ to nearly the same extent as in the control $[50 \pm 3 \%$ compared with $55 \pm 6 \%$ in control $(n=3$; $p>0.2)$ for $\tau_{\mathrm{des}} ; 68.5 \pm 3 \%$ compared with $56 \pm 5 \%$ in control (Fig. $5 b, e)(n=3 ; p>$ $0.4)$ for $\left.t_{\mathrm{on}}\right]$. Inhibition of $I_{\mathrm{Gly}}$ peak amplitude was also not significantly different from control numbers $52 \pm 2 \%$ compared with $40 \pm 7 \%$ in control; $n=3 ; p>$ $0.2)$. Altogether, these data are consistent with a direct action of cannabinoids on GlyRs. In addition, the mapping studies in rat brain showed that CB1Rs are mainly localized to axons and nerve terminals and are essentially absent on the neuronal soma or dendrites (Tsou et al., 1998).

\section{GlyR-driven seizure-like rhythmic} activity in hippocampal slices

The function of GlyRs in the hippocampus is not clear. It is possible that these receptors mediate neuronal function in a manner similar to $\mathrm{GABA}_{\mathrm{A}} \mathrm{Rs}$. Numerous reports indicate that $\mathrm{GABA}_{\mathrm{A}} \mathrm{Rs}$ and GlyRs, principal inhibitory receptors, when in-
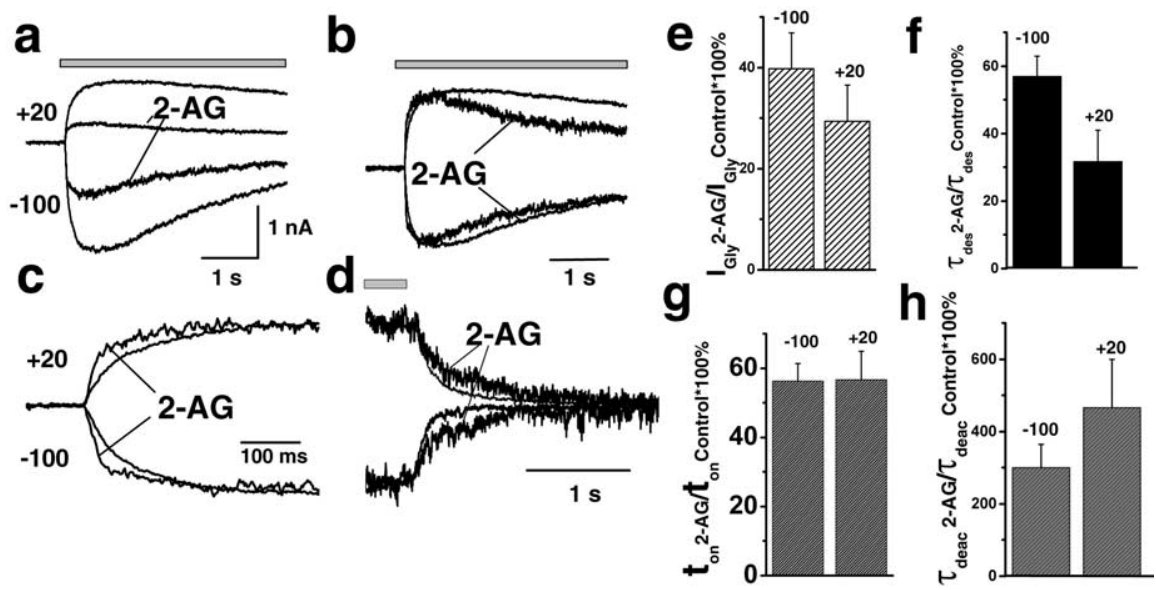

Figure 3. Voltage dependence of the $I_{G l y}$ modulation by 2-AG. $\boldsymbol{a}$, Representative traces obtained in control condition and in the presence of $1 \mu \mathrm{m}$ 2-AG at holding potentials of -100 and $+20 \mathrm{mV} . \boldsymbol{b}, \boldsymbol{c}$, Corresponding traces normalized and superimposed. $\boldsymbol{d}$, Deactivation of $I_{\text {Gly }}$ before and after preapplication with 2-AG. $\boldsymbol{e}-\boldsymbol{h}$, Statistics for the 2-AG effects on peak amplitude $(\boldsymbol{e}), \boldsymbol{\tau}_{\text {des }}(\boldsymbol{f})$, $t_{\text {on }}(\boldsymbol{g})$, and $\tau_{\text {deac }}(\boldsymbol{h})$ obtained at holding potentials of -100 and $+20 \mathrm{mV}$. a
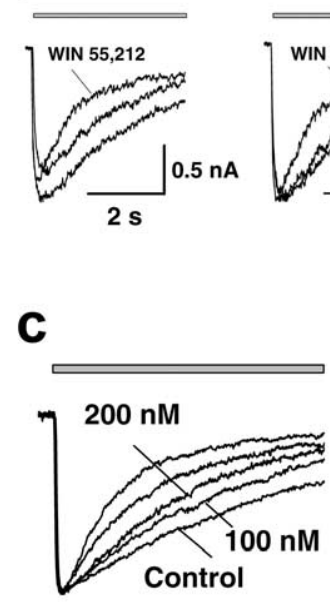

$1 \mathrm{~s}$
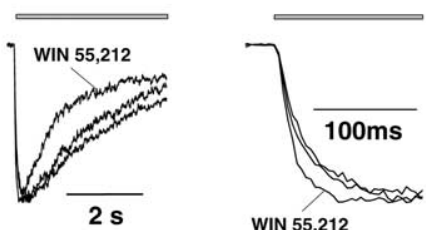

WIN 55,212

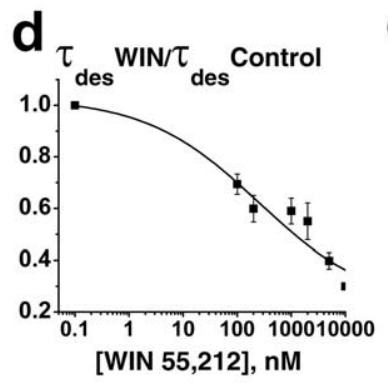

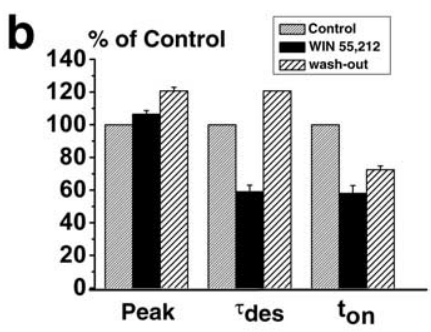

e

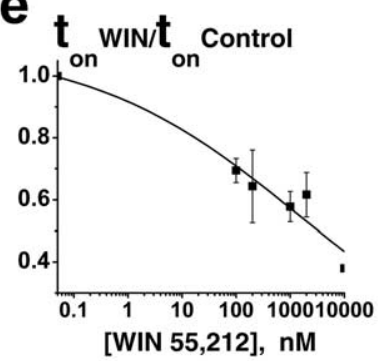

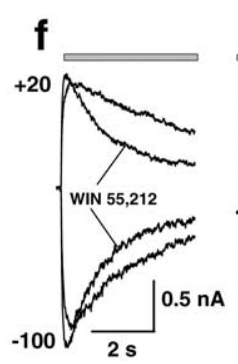
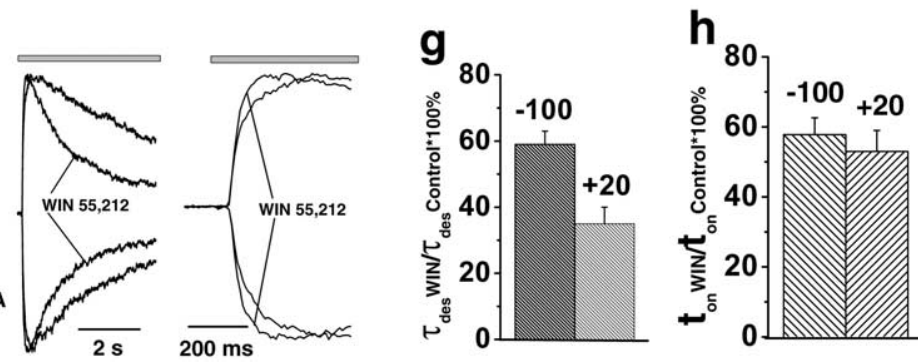

Figure 4. Modulation of glycine-activated currents by WIN 55,212-2. $\boldsymbol{a}$, Left, Traces of $I_{\text {Gly }}$ induced by $100 \mu \mathrm{M}$ Gly obtained in control, in the presence of WIN 55,212-2 (1 $\mu \mathrm{m})$, and after washout of drug (gray line) $\left(V_{\mathrm{h}}=-100 \mathrm{mV}\right)$. Middle and right, The same traces are superimposed and normalized. $\boldsymbol{b}$, Statistics of the effects of WIN 55,212-2 on the amplitude, $\tau_{\text {des }}$, and $t_{\text {on }}(n=11)$ of $I_{\text {Gly }} \cdot \boldsymbol{c}-\boldsymbol{e}$, Concentration dependence of the WIN 55,212-2 effects on $I_{\text {Gly }}$ kinetics. $\boldsymbol{c}, I_{\text {Gly }}$ traces recorded at various concentration of WIN 55,212-2 ranged from $100 \mathrm{~nm}$ to $2 \mu \mathrm{m}$ measured in the same cell are normalized and superimposed. $\boldsymbol{d}, \boldsymbol{e}$, Summary plots showing the effect of increasing the WIN 55,212-2 concentrations on $\tau_{\text {des }}(\boldsymbol{d})$ and $t_{\text {on }}(\boldsymbol{e})$ measured at $V_{\mathrm{h}}=-100 \mathrm{mV}(n=4)$. Data are plotted as a fraction of the maximal glycine current in control. $\boldsymbol{f}$ - $\boldsymbol{h}$, Voltage dependence of the $I_{\text {Gly }}$ modulation by the WIN $55,212-2$. $f$, Left, $I_{\text {Gly }}$ representative traces obtained in control condition and in the presence of $1 \mu \mathrm{m}$ WIN 55,212-2 at holding potentials of $-100 \mathrm{mV}$ and $+20 \mathrm{mV}$. Middle and right, The same traces are superimposed and normalized. Statistics for the WIN $55,212-2$ effects on $\tau_{\text {des }}(\boldsymbol{g})$ and $t_{\text {on }}(\boldsymbol{h})$ at holding voltages of -100 and $+20 \mathrm{mV}$. 
a
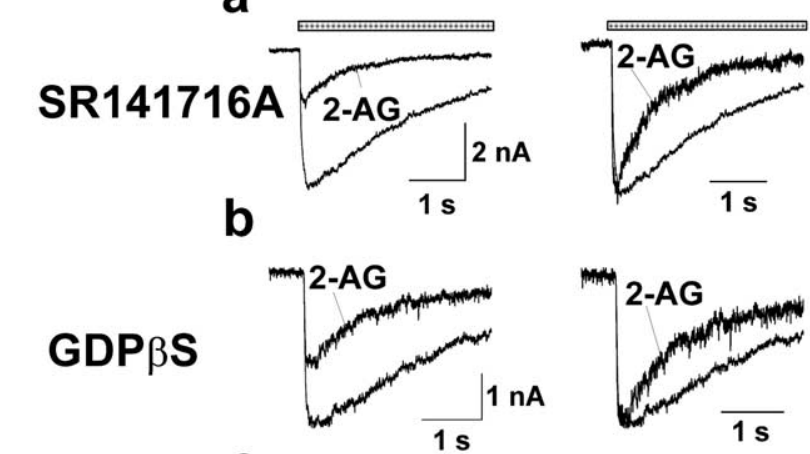

C

$1 \mathrm{~s}$

$1 \mathrm{~s}$

CPZ
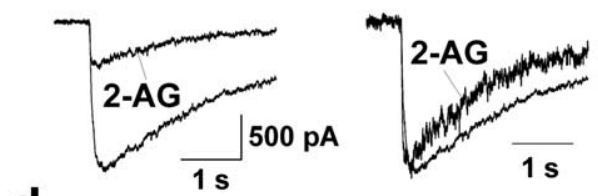

$1 \mathrm{~s}$

d

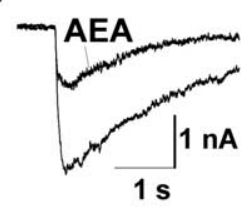

CPZ

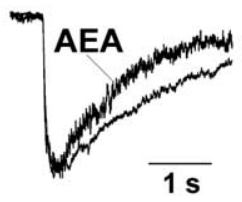

s

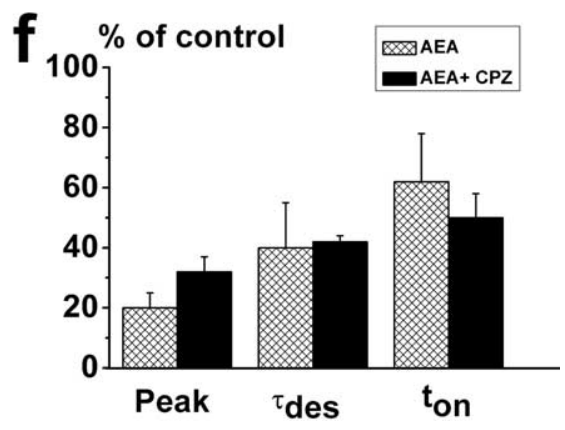

Figure 5. CB1/CB3 receptors and $G$-proteins are not involved in the modulation of $I_{G l y}$ by cannabinoids. $\boldsymbol{a}-\boldsymbol{c}$, Left, Traces of $I_{G l y}$ $(100 \mu \mathrm{M})$ obtained in the control and with $1 \mu \mathrm{m} 2-A G$ in the presence of SR141716A (2 $\mu \mathrm{M})(\boldsymbol{a})$, intracellularly preapplied GDP $\beta S$ $(2 \mathrm{~mm})(\boldsymbol{b})$, and capsazepine $(C P Z ; 1 \mu \mathrm{M})(\boldsymbol{c}) . V_{\mathrm{h}}=-100 \mathrm{mV}$. Middle and right, The same traces are superimposed and normalized. $\boldsymbol{e}$, Statistics of the effects of 2-AG on the peak amplitude, $\tau_{\text {des, }}$ and $t_{\text {on }}(n=4)$ of $I_{\text {Gly }}$ in the presence of SR141716A,

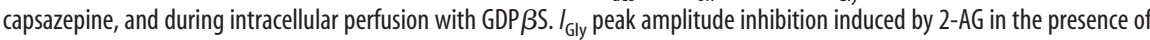
SR141716A was $46 \pm 9 \%$ compared with $40 \pm 7 \%$ in control $(n=3 ; p>0.5)$, whereas corresponding figures for $\tau_{\text {des }}$ were $55 \pm$ $4 \%$ in the presence of antagonist compared with $55 \pm 6 \%(n=3 ; p>0.8)$, and $t_{\text {on }}$ was $54 \pm 9 \%$ compared with $56 \pm 5 \%(n=$ $3 ; p>1)$. $d$, Left, Traces of $I_{\text {Gly }}(100 \mu \mathrm{m})$ obtained in the control and with $1 \mu \mathrm{m}$ AEA in the presence of $1 \mu \mathrm{m}$ capsazepine (CPZ). Middle and right, The same traces are superimposed and normalized. $f$, Statistics of the effects of AEA on the peak amplitude, $\tau_{\text {des }}$ and $t_{\text {on }}$ of $I_{G l y}$ in the presence of $C P Z$. In the presence of $C P Z$, decay kinetics and rise time were accelerated by $A E A$ to nearly the same extent as in the control: $42 \pm 2 \%$ compared with $40 \pm 15 \%$ in control $(n=3 ; p>0.8)$ for $\tau_{\text {des }} ; 50 \pm 8 \%$ compared with $62 \pm$ $16 \%$ in control $(n=3 ; p>0.7)$ for $t_{\text {on }}$.

tensely activated, excite rather than inhibit neurons (Alger and Nicoll, 1979; Staley et al., 1995; Kaila et al., 1997; Taira et al., 1997; Backus et al., 1998). It has been shown that excitatory GABAergic transmission seems to play an active functional role in the generation of seizure-like rhythmic activity in the hippocampus (Grover et al., 1993; Staley et al., 1995). We hypothesized that in conditions of intense activation, GlyRs could also participate in processes of synchronization of neuronal activity. To address the functional implication of the direct action of cannabinoids on GlyRs in the hippocampus, we tested the possibility that GlyRs are involved in seizure-like activity induced by high-frequency stimulation in the presence of bicuculline and, if so, whether they are then modulated by application of cannabinoids.

CA1 field network activity was induced by repetitive stimulation with short bursts of high-frequency stimulation (seven stimuli at $50 \mathrm{~Hz}$ ) applied to the Schaffer collateral-commissural pathway with a 4 min interval in the presence of bicuculline $(20-40 \mu \mathrm{M})$ (Fig. 6). This type of stimulation protocol imitates natural patterns of activity (Ranck, 1973). Seizure-like events lasted for 1-4 s after burst stimulation and can be classified as intermediate ictal activity $(>500 \mathrm{~ms}$, interictal; $<4 \mathrm{~s}$, ictal) (Traub et al., 1996). Experiments in which the CA3 zone was surgically cut revealed that this type of activity originated in the CA3 zone, being completely eliminated in minislices (Fig. 6a). Seizure-like activity was completely blocked by antagonists of excitatory transmission, 2,3-dihydroxy-6nitro-7-sulfonyl-benzo[f] quinoxaline-7sulfonamide $(20 \mu \mathrm{M})$ or D-AP-5 $(50 \mu \mathrm{M}$; $n=5$ ). Our experiments revealed that seizure-like activity was disrupted by strychnine $(5-10 \mu \mathrm{M})$ (Fig. 6b) and selective GlyR antagonists ginkgolide B $(10-20 \mu \mathrm{M})$ and ginkgolide $\mathrm{J}(50-70 \mu \mathrm{M})$ (data not shown). Correspondingly, the power of hippocampal epileptiform activity decreased in the presence of antagonists (Fig. $6 e, h)$.

It has been shown that the $\mathrm{GABA}_{\mathrm{A}} \mathrm{R}$ mediated excitatory response is a result of an asymmetric, activity-dependent collapse of the opposing electrochemical gradients of two anions $\left(\mathrm{Cl}^{-}\right.$and $\left.\mathrm{HCO}_{3}\right)$ that permeate a $\mathrm{GABA}_{\mathrm{A}} \mathrm{R}$ channel (Bormann et al., 1987; Kaila and Voipio, 1987). We presumed that depolarizing, GlyR-activated, $\mathrm{HCO}_{3}$-carried currents, as in the case of GABA $_{\mathrm{A}}$ Rs (Bormann et al., 1987; Staley et al., 1995; Kaila et al., 1997), could be involved in the generation of strychninesensitive seizure-like activity. To prove this hypothesis, we conducted experiments in nominally $\mathrm{CO}_{2} / \mathrm{HCO}_{3}$-free medium. After 20-30 min of perfusion with HEPES-buffered solution saturated with $100 \% \mathrm{O}_{2}$, seizure-like activity was strongly attenuated (Fig. $6 c, f, i)$. This observation is consistent with a key role for $\mathrm{HCO}_{3}$ in the generation of the depolarizing response.

\section{Modulation of hippocampal GlyR-driven epileptiform activity by cannabinoids}

In line with strong inhibitory action of cannabinoids on $I_{\mathrm{Gly}} \mathrm{ob}-$ served in isolated neurons, GlyR-driven epileptiform activity was also significantly impaired by high concentrations of AEA (10-20 $\mu \mathrm{M}$ ) in control conditions and in the presence of CB1 receptor antagonist SR141716A (Fig. 6d). The maximal power of hippocampal epileptiform activity (frequency, $\sim 10 \mathrm{~Hz}$ ) decreased in 
the presence of AEA in control to $31 \pm 9 \%$ $(n=4)$ compared with $54 \pm 8 \%(n=4)$, in the presence of SR141716A (Fig. $6 g, j$ ). Concentrations of AEA used in this set of experiments were higher than those in experiments using isolated cells to overcome the enzymatic attack of fatty acid amide hydrolase, which breaks down anandamide into arachidonic acid and ethanolamine (Hillard et al., 1995).

WIN 55,212-2 at a high concentration $(10 \mu \mathrm{M})$, which produced significant inhibition of $I_{\mathrm{Gly}}$ amplitude, attenuated seizure-like activity in the hippocampus in the same way as AEA (data not shown). These results suggest the possibility of modulation of the GlyR-mediated network activity by cannabinoids.

\section{Discussion}

Here, we report that cannabinoids strongly modulate gating of GlyRactivated chloride channels in isolated hippocampal pyramidal and Purkinje neurons. Thus, in addition to the well known retrograde mode of cannabinoid action activating presynaptic CB1Rs (which implies diffusion of a messenger from postsynaptic elements backwards to the presynaptic cell), the present results show a novel, direct action of endocannabinoids on GlyRs. These receptors can be located in close proximity to the point of release of cannabinoids from the postsynaptic cell and may serve as a target for cannabinoid signaling.

Glycinergic synapses are found in many CNS regions, including the spinal cord, brainstem, and cerebellum (Jonas et al., 1998; Chery and de Koninck, 1999; O'Brien and Berger, 1999), where they play a well established role in the processing of motor and sensory information that controls movement, vision, and audition (Aprison, 1990; Moss and Smart, 2001). Our results suggest that this transmission can be directly modulated by endogenously released cannabinoids. The machineries necessary for both synaptic and nonsynaptic GlyR-mediated transmission have been reported to be present in the hippocampus. In particular, synaptoneurosomes obtained from adult rat hippocampus contain glycine and release it by both vesicular and nonvesicular mechanisms (Burger et al., 1991; Engblom et al., 1996). Expression of $\beta$ heteromeric GlyRs in the developing hippocampus (Malosio et al., 1991; Chattipakorn and McMahon, 2002; Kondratskaya et al., 2004) indicate the synaptic location of GlyRs, because the $\beta$ subunit is required for receptor clustering (Kirsch et al., 1993; Meyer et al., 1995). Recent immunocytochemical studies demonstrate both synaptic and nonsynaptic expression of GlyRs in the hippocampus (Brackmann et al., 2004). Finally, colocalization of glycine transporters and GlyRs in
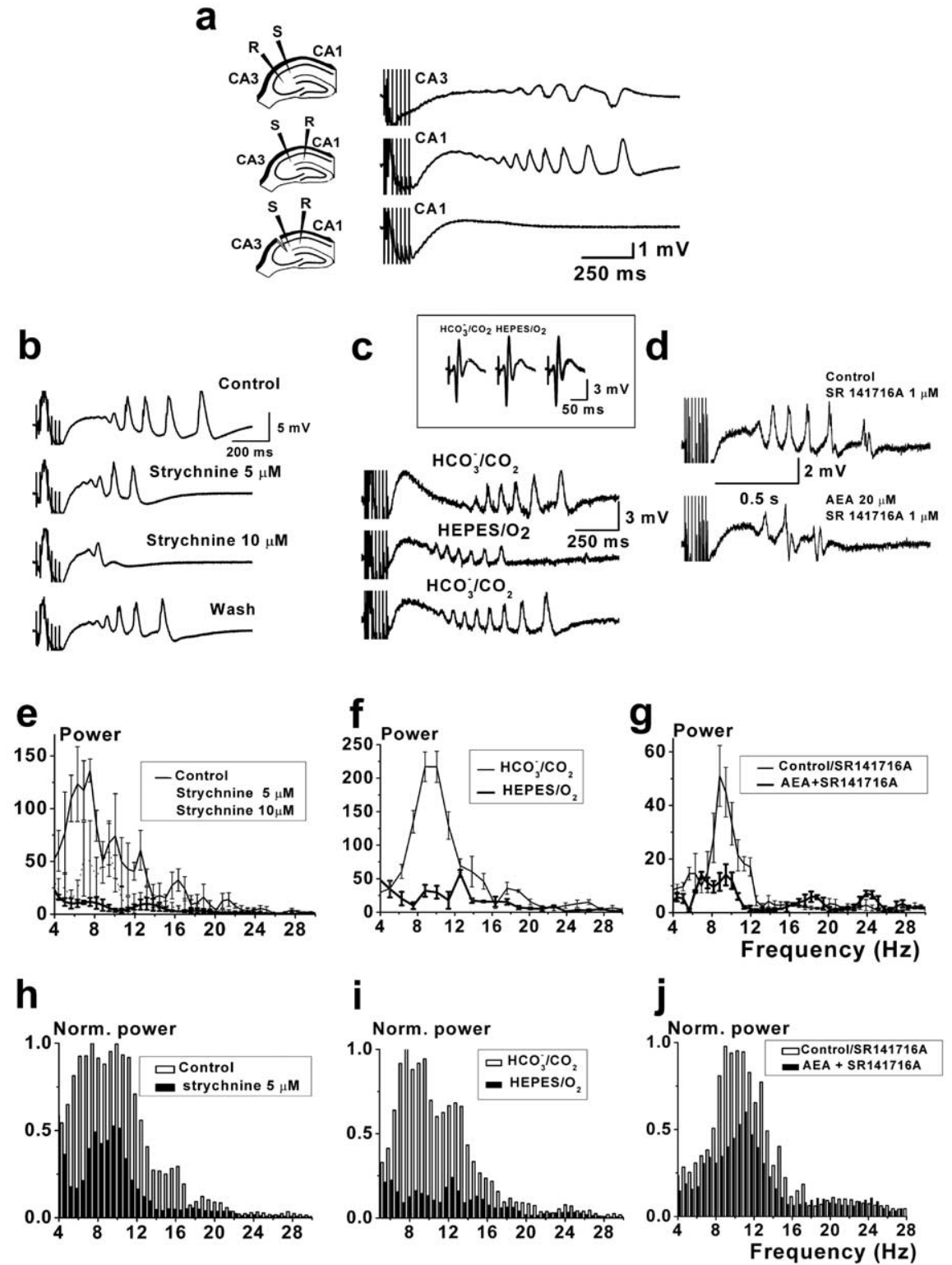

Figure 6. GlyR-driven seizure-like rhythmic activities in hippocampal slices attenuated by AEA. $\boldsymbol{a}$, Seizure-like activity recorded from CA1 and CA3 stratum radiatum in response to stimulation $(S)$ of Schaffer collateral-commissural pathway with highfrequency short trains of stimuli ( 7 stimuli; $50 \mathrm{~Hz}$ ) applied every $4 \mathrm{~min}$ in the presence of $30 \mu \mathrm{m}$ bicuculline. Slice events were detected by using extracellular field potential recordings (R). Cutting the Schaffer collaterals abolishes discharges in the CA1 area, indicating that excitatory inputs from the CA3 area are necessary for entraining CA1 to generate the epileptiform discharges. Traces of epileptiform discharges in control and in the presence of strychnine $(\boldsymbol{b})$ and AEA (20 $\mu \mathrm{M})$ against the background of SR141716A (1 $\mu \mathrm{M})(\boldsymbol{d})$ are shown. c, Experiment demonstrating attenuation of epileptiform activity after 30 min of perfusion in nominally $\mathrm{CO}_{2}$-free superfusion medium. Note that control field potentials, evoked by single stimuli stimulation of Shaffer collateral-commissural pathway (no bicuculline), did not change after changing of superfusion medium (inset). $\boldsymbol{e}$ - $\boldsymbol{g}$, Corresponding averaged Fourier transformations (4 epochs of 2 s recordings) of epileptiform activity. $\boldsymbol{h}-\boldsymbol{j}$, The normalized summarized Fourier transformations of 2-s-long epochs of epileptiform discharges at $\beta$-frequency bands in control and in the presence of strychnine $(5 \mu \mathrm{m} ; n=5)(\boldsymbol{h})$, in $\mathrm{CO}_{2}$-free medium $(n=3)(\boldsymbol{i})$, and in the presence of AEA and SR141716A $(n=4)(\boldsymbol{j})$.

the hippocampus (Jursky and Nelson, 1995) suggests the possibility that extrasynaptic GlyRs could be activated by reverse uptake of glycine. Few reports suggest the possibility that GlyRs may mediate the inhibitory effects of glycine in the hippocampus (Cherubini et al., 1981; Seiler and Sarhan, 1984; Chattipakorn and McMahon, 2003). Nevertheless, to date, the physiological role for and conditions under which GlyRs are activated in the hippocampus were unknown.

Our data show that seizure-like activity induced by repetitive 
high-frequency short-burst stimulation in the presence of bicuculline in the CA1 zone of hippocampal slices revealed paradoxal sensitivity to GlyR antagonists, indicating that GlyRs drive this activity. We suggest that GlyRergic excitation can participate in the expression of seizure-like rhythmic synchronization in the hippocampus. This hypothesis was supported by our finding that strychnine-sensitive slice events were eliminated in $\mathrm{CO}_{2} / \mathrm{HCO}_{3}$ nominally free medium, indicating that $\mathrm{HCO}_{3}$ ions are the major driven anions for seizure expression. Therefore, it is possible to suggest that inhibition of GlyRs induced by cannabinoids could result either in a decrease in the amount of synaptic GlyRmediated excitatory drive necessary for synchronized behavior or, if extrasynaptic GlyRs are the main players, in the decrease of tonic excitability and shift of seizure threshold. Thus, in either the extrasynaptic or synaptic scenario, inhibition of GlyRs would lead to a disruption of network activity. Indeed, GlyR antagonistsensitive epileptiform activity was depressed by AEA. The latter finding is in agreement with the previous observation that both WIN 55,212-2 and AEA inhibited interictal activity induced by low- $\mathrm{Mg}^{2+} /$ high- $\mathrm{K}^{+}$medium recorded in the CA1 stratum pyramidale of the hippocampus (Ameri et al., 1999).

Acceleration of desensitization of $I_{\mathrm{Gly}}$ by cannabinoids is of particular interest. Both homo-oligomeric and heterooligomeric GlyRs display slow desensitization with a slow recovery. This suggests that the time course and the amplitude of glycinergic miniature IPSCs will only be slightly affected by desensitization. Desensitization of homomeric $\alpha 1$ GlyR has been shown by others to be more prominent with increased receptor density (Legendre et al., 2002) and with phosphorylation of the receptor (Gentet and Clements, 2002). In both of these studies, acceleration of desensitization was reported to prolong the current relaxation time course. Slow desensitization of GlyRs cannot play a significant role after release of a single vesicle. However, it might contribute to glycinergic synaptic efficacy when a longlasting (seconds-range) depolarization of the postsynaptic membrane is coupled with high-frequency cell activity (Legendre, 1998). Moreover, the prolonged deactivation phase of glycinergic events should act to reinforce the efficacy of inhibition.

Slowdown of $I_{\text {Gly }}$ deactivation could also have important consequences for inhibitory network behavior, because the rate of decay of synaptic responses can significantly alter firing frequency and the ability of the network to synchronize (Wang and Rinzel, 1992; Wang and Buzsaki, 1996).

The time course of synaptic conductance is an important determinant of the temporal precision of information processing within a neuronal network. Synaptic integration depends on the duration of the EPSPs, because this determines both the time window within which they summate to reach spike threshold and the temporal precision of spike generation (Fricker and Miles, 2000; Galarreta and Hestrin, 2001) and the efficacy of information transfer (London et al., 2002). This is important because fast EPSPs allow neurons to behave as coincidence detectors, whereas neurons with slow EPSPs may behave as temporal integrators (Geiger et al., 1997; Trussell, 1997; Taschenberger and von Gersdorff, 2000). In particular, interaction between excitatory and inhibitory action provides a mechanism for processing auditory temporal information. Blocking GABAergic or glycinergic inhibition can eliminate duration tuning, suggesting that the neural code for sound duration is the result of convergence of excitatory and inhibitory inputs (Casseday et al., 2000). The matching of excitatory transmission in the calyx of Held by a powerful, precision glycinergic inhibitory system suggests that the relay function of the medial nucleus of the trapezoid body of rats may be rapidly modified during sound localization (Awatramani et al., 2004).

In the case of the "extrasynaptic scenario," prolonged depolarization induced by tonic activation of extrasynaptic GlyRs would be decreased in the presence of cannabinoids, resulting in decreased neuronal excitability. Inhibition of tonic GlyRmediated conductance can lead to attenuation of membrane conductance and slowdown of the EPSC decay that is crucial for temporal summation.

Altogether, our findings suggest a fundamental importance of GlyR in hippocampal network activity and nominate GlyR as a novel target for endocannabinoid signaling.

\section{References}

Adams IB, Compton DR, Martin BR (1998) Assessment of anandamide interaction with the cannabinoid brain receptor: SR 141716A antagonism studies in mice and autoradiographic analysis of receptor binding in rat brain. J Pharmacol Exp Ther 284:1209-1217.

Akaike N, Kaneda M (1989) Glycine-gated chloride current in acutely isolated rat hypothalamic neurons. J Neurophysiol 62:1400-1409.

Alger BE, Nicoll RA (1979) GABA-mediated biphasic inhibitory responses in hippocampus. Nature 281:315-317.

Ameri A, Wilhelm A, Simmet T (1999) Effects of the endogeneous cannabinoid, anandamide, on neuronal activity in rat hippocampal slices. Br J Pharmacol 126:1831-1839.

Aprison MH (1990) The discovery of the neurotransmitter role of glycine. In: Glycine transmission (Ottersen OP, Storm-Mathisen J, eds), pp 1-24. New York: Wiley.

Awatramani GB, Turecek R, Trussell LO (2004) Inhibitory control at a synaptic relay. J Neurosci 24:2643-2647.

Backus KH, Deitmer JW, Friauf E (1998) Glycine-activated currents are changed by coincident membrane depolarization in developing rat auditory brainstem neurones. J Physiol (Lond) 507:783-794.

Baskfield CY, Martin BR, Wiley JL (2004) Differential effects of delta9tetrahydrocannabinol and methanandamide in CB1 knockout and wildtype mice. J Pharmacol Exp Ther 309:86-91.

Bormann J, Hamill OP, Sakmann B (1987) Mechanism of anion permeation through channels gated by glycine and gamma-aminobutyric acid in mouse cultured spinal neurones. J Physiol (Lond) 385:243-286.

Brackmann M, Zhao C, Schmieden V, Braunewell KH (2004) Cellular and subcellular localization of the inhibitory glycine receptor in hippocampal neurons. Biochem Biophys Res Commun 324:1137-1142.

Burger PM, Hell J, Mehl E, Krasel C, Lottspeich F, Jahn R (1991) GABA and glycine in synaptic vesicles: storage and transport characteristics. Neuron 7:287-293.

Casseday JH, Ehrlich D, Covey E (2000) Neural measurement of sound duration: control by excitatory-inhibitory interactions in the inferior colliculus. J Neurophysiol 84:1475-1487.

Chattipakorn SC, McMahon LL (2002) Pharmacological characterization of glycine-gated chloride currents recorded in rat hippocampal slices. J Neurophysiol 87:1515-1525.

Chattipakorn SC, McMahon LL (2003) Strychnine-sensitive glycine receptors depress hyperexcitability in rat dentate gyrus. J Neurophysiol 89:1339-1342.

Cherubini E, Bernardi G, Stanzione P, Marciani MG, Mercuri N (1981) The action of glycine on rat epileptic foci. Neurosci Lett 21:93-97.

Chery N, de Koninck Y (1999) Junctional versus extrajunctional glycine and $\mathrm{GABA}_{\mathrm{A}}$ receptor-mediated IPSCs in identified lamina I neurons of the adult rat spinal cord. J Neurosci 19:7342-7355.

Chevaleyre V, Castillo PE (2004) Endocannabinoid-mediated metaplasticity in the hippocampus. Neuron 43:871-881.

Devane WA, Hanus L, Breuer A, Pertwee RG, Stevenson LA, Griffin G, Gibson D, Mandelbaum A, Etinger A, Mechoulam R (1992) Isolation and structure of a brain constituent that binds to the cannabinoid receptor. Science 258:1946-1949.

Diana MA, Levenes C, MacKie K, Marty A (2002) Short-term retrograde inhibition of GABAergic synaptic currents in rat Purkinje cells is mediated by endogenous cannabinoids. J Neurosci 22:200-208.

Di Marzo V, Fontana A, Cadas H, Schinelli S, Cimino G, Schwartz JC, Piomelli D (1994) Formation and inactivation of endogenous cannabinoid anandamide in central neurons. Nature 372:686-691. 
Engblom AC, Eriksson KS, Akerman KE (1996) Glycine and $\mathrm{GABA}_{\mathrm{A}}$ receptor-mediated chloride fluxes in synaptoneurosomes from different parts of the rat brain. Brain Res 712:74-83.

Fricker D, Miles R (2000) EPSP amplification and the precision of spike timing in hippocampal neurons. Neuron 28:559-569.

Galarreta M, Hestrin S (2001) Spike transmission and synchrony detection in networks of GABAergic interneurons. Science 292:2295-2299.

Geiger JR, Lubke J, Roth A, Frotscher M, Jonas P (1997) Submillisecond AMPA receptor-mediated signaling at a principal neuron-interneuron synapse. Neuron 18:1009-1023.

Gentet LJ, Clements JD (2002) Binding site stoichiometry and the effects of phosphorylation on human alphal homomeric glycine receptors. J Physiol (Lond) 544:97-106.

Grover LM, Lambert NA, Schwartzkroin PA, Teyler TJ (1993) Role of HCO3- ions in depolarizing $\mathrm{GABA}_{\mathrm{A}}$ receptor-mediated responses in pyramidal cells of rat hippocampus. J Neurophysiol 69:1541-1555.

Hajos N, Katona I, Naiem SS, MacKie K, Ledent C, Mody I, Freund TF (2000) Cannabinoids inhibit hippocampal GABAergic transmission and network oscillations. Eur J Neurosci 12:3239-3249.

Hajos N, Ledent C, Freund TF (2001) Novel cannabinoid-sensitive receptor mediates inhibition of glutamatergic synaptic transmission in the hippocampus. Neuroscience 106:1-4.

Hillard CJ, Wilkison DM, Edgemond WS, Campbell WB (1995) Characterization of the kinetics and distribution of $\mathrm{N}$-arachidonylethanolamine (anandamide) hydrolysis by rat brain. Biochim Biophys Acta 1257:249-256.

Hoffman AF, Lupica CR (2000) Mechanisms of cannabinoid inhibition of $\mathrm{GABA}_{\mathrm{A}}$ synaptic transmission in the hippocampus. J Neurosci 20:2470-2479.

Jonas P, Bischofberger J, Sandkuhler J (1998) Corelease of two fast neurotransmitters at a central synapse. Science 281:419-424.

Jones MV, Westbrook GL (1995) Desensitized states prolong $\mathrm{GABA}_{\mathrm{A}}$ channel responses to brief agonist pulses. Neuron 15:181-191.

Jursky F, Nelson N (1995) Localization of glycine neurotransmitter transporter (GLYT2) reveals correlation with the distribution of glycine receptor. J Neurochem 64:1026-1033.

Kaila K, Voipio J (1987) Postsynaptic fall in intracellular pH induced by GABA-activated bicarbonate conductance. Nature 330:163-165.

Kaila K, Lamsa K, Smirnov S, Taira T, Voipio J (1997) Long-lasting GABAmediated depolarization evoked by high-frequency stimulation in pyramidal neurons of rat hippocampal slice is attributable to a networkdriven, bicarbonate-dependent $\mathrm{K}^{+}$transient. J Neurosci 17:7662-7672.

Kirsch J, Wolters I, Triller A, Betz H (1993) Gephyrin antisense oligonucleotides prevent glycine receptor clustering in spinal neurons. Nature 366:745-748.

Kondratskaya EL, Lishko PV, Chatterjee SS, Krishtal OA (2002) BN52021, a platelet activating factor antagonist, is a selective blocker of glycine-gated chloride channel. Neurochem Int 40:647-653.

Kondratskaya EL, Fisyunov AI, Chatterjee SS, Krishtal OA (2004) Ginkgolide B preferentially blocks chloride channels formed by heteromeric glycine receptors in hippocampal pyramidal neurons of rat. Brain Res Bull 63:309-314.

Kreitzer AC, Regehr WG (2001) Retrograde inhibition of presynaptic calcium influx by endogenous cannabinoids at excitatory synapses onto Purkinje cells. Neuron 29:717-727.

Krishtal OA, Marchenko SM, Pidoplichko VI (1983) Receptor for ATP in the membrane of mammalian sensory neurones. Neurosci Lett 35:41-45.

Krishtal OA, Osipchuk Y, Vrublevsky SV (1988) Properties of glycineactivated conductances in rat brain neurones. Neurosci Lett 84:271-276.

Legendre P (1998) A reluctant gating mode of glycine receptor channels determines the time course of inhibitory miniature synaptic events in zebrafish hindbrain neurons. J Neurosci 18:2856-2870.

London M, Schreibman A, Hausser M, Larkum ME, Segev I (2002) The information efficacy of a synapse. Nat Neurosci 5:332-340.
Mahmoudian M (1997) The cannabinoid receptor: computer-aided molecular modeling and docking of ligand. J Mol Graph Model 15:149-153, 179.

Malosio ML, Marqueze-Pouey B, Kuhse J, Betz H (1991) Widespread expression of glycine receptor subunit mRNAs in the adult and developing rat brain. EMBO J 10:2401-2409.

Meyer G, Kirsch J, Betz H, Langosch D (1995) Identification of a gephyrin binding motif on the glycine receptor beta subunit. Neuron 15:563-572.

Misner DL, Sullivan JM (1999) Mechanism of cannabinoid effects on longterm potentiation and depression in hippocampal CA1 neurons. J Neurosci 19:6795-6805.

Moss SJ, Smart TG (2001) Constructing inhibitory synapses. Nat Rev Neurosci 2:240-250.

Munro S, Thomas KL, Abu-Shaar M (1993) Molecular characterization of a peripheral receptor for cannabinoids. Nature 365:61-65.

O’Brien JA, Berger AJ (1999) Cotransmission of GABA and glycine to brain stem motoneurons. J Neurophysiol 82:1638-1641.

Ohno-Shosaku T, Maejima T, Kano M (2001) Endogenous cannabinoids mediate retrograde signals from depolarized postsynaptic neurons to presynaptic terminals. Neuron 29:729-738.

Ranck JBJ (1973) Studies on single neurons in dorsal hippocampal formation and septum in unrestrained rats. I. Behavioral correlates and firing repertoires. Exp Neurol 41:461-531.

Seiler N, Sarhan S (1984) Synergistic anticonvulsant effects of a GABA agonist and glycine. Gen Pharmacol 15:367-369.

Shim JY, Welsh WJ, Howlett AC (2003) Homology model of the CB1 cannabinoid receptor: sites critical for nonclassical cannabinoid agonist interaction. Biopolymers 71:169-189.

Shirasaki T, Klee MR, Nakaye T, Akaike N (1991) Differential blockade of bicuculline and strychnine on GABA- and glycine-induced responses in dissociated rat hippocampal pyramidal cells. Brain Res 561:77-83.

Staley KJ, Soldo BL, Proctor WR (1995) Ionic mechanisms of neuronal excitation by inhibitory $\mathrm{GABA}_{\mathrm{A}}$ receptors. Science 269:977-981.

Stella N, Schweitzer P, Piomelli D (1997) A second endogenous cannabinoid that modulates long-term potentiation. Nature 388:773-778.

Taira T, Lamsa K, Kaila K (1997) Posttetanic excitation mediated by GABA receptors in rat CA1 pyramidal neurons. J Neurophysiol 77:2213-2218.

Tao Q, McAllister SD, Andreassi J, Nowell KW, Cabral GA, Hurst DP, Bachtel K, Ekman MC, Reggio PH, Abood ME (1999) Role of a conserved lysine residue in the peripheral cannabinoid receptor (CB2): evidence for subtype specificity. Mol Pharmacol 55:605-613.

Taschenberger H, von Gersdorff H (2000) Fine-tuning an auditory synapse for speed and fidelity: developmental changes in presynaptic waveform, EPSC kinetics, and synaptic plasticity. J Neurosci 20:9162-9173.

Traub RD, Borck C, Colling SB, Jefferys JG (1996) On the structure of ictal events in vitro. Epilepsia 37:879-891.

Trussell LO (1997) Cellular mechanisms for preservation of timing in central auditory pathways. Curr Opin Neurobiol 7:487-492.

Tsou K, Brown S, Sanudo-Pena MC, MacKie K, Walker JM (1998) Immunohistochemical distribution of cannabinoid CB1 receptors in the rat central nervous system. Neuroscience 83:393-411.

Wang XJ, Buzsaki G (1996) Gamma oscillation by synaptic inhibition in a hippocampal interneuronal network model. J Neurosci 16:6402-6413.

Wang X-L, Rinzel J (1992) Alternating and synchronous rhythms in reciprocally inhibitory model neurons. Neural Comput 4:84-97.

Wilson RI, Nicoll RA (2001) Endogenous cannabinoids mediate retrograde signalling at hippocampal synapses. Nature 410:588-592.

Wilson RI, Nicoll RA (2002) Endocannabinoid signaling in the brain. Science 296:678-682.

Zygmunt PM, Petersson J, Andersson DA, Chuang H, Sorgard M, Di Marzo V, Julius D, Hogestatt ED (1999) Vanilloid receptors on sensory nerves mediate the vasodilator action of anandamide. Nature 400:452-457.

Zygmunt PM, Julius I, Di M, I, Hogestatt ED (2000) Anandamide-the other side of the coin. Trends Pharmacol Sci 21:43-44. 